\title{
Patterns of Sensitization to Inhalant Allergens in Japanese Lower-Grade Schoolchildren and Related Factors
}

\author{
Shin Yamazaki ${ }^{a}$ Masayuki Shima $^{c}$ Toshio Nakadate $^{d}$ Toshimasa Ohara $^{b}$ \\ Takashi Omori $^{\mathrm{e}}$ Masaji Ono $^{\mathrm{a}}$ Tosiya Sato $^{f}$ Hiroshi Nitta $^{\mathrm{a}}$ \\ ${ }^{a}$ Center for Environmental Health Sciences and b Planning Department, National Institute for Environmental Studies, \\ Tsukuba, ' ${ }^{C}$ Department of Public Health, Hyogo College of Medicine, Nishinomiya, ${ }^{d}$ Department of Hygiene, Showa \\ University School of Medicine, Tokyo, ${ }^{e}$ Center Administration Division, Center for Clinical Research, Kobe University \\ Hospital, Kobe, and f Department of Biostatistics, Kyoto University School of Public Health, Kyoto, Japan
}

\section{Key Words}

Allergy · Children · Epidemiology · Specific lgE

\begin{abstract}
Objective: This study clarified sensitization patterns to house dust mite (HDM) and Japanese cedar pollen (JCP) in Japanese lower-grade schoolchildren. We also explored factors associated with allergic sensitization. Methods: This cross-sectional study used a database from the Study on Respiratory Disease and Automobile Exhaust (SORA), a Japanese health study project. The subjects comprised 8,815 pupils aged 6-9 years. We obtained the distribution of HDM- and JCP-specific lgE, respectively, as a marker of sensitization. To determine factors associated with sensitization, we used logistic regression and calculated adjusted odds ratios (AORs) for the relative prevalence of sensitization. The cut-off point for specific lgE levels was $0.35 \mathrm{kU} / \mathrm{l}$. Results: Sensitization to HDM and JCP was detected in 51 and 39\% of subjects, respectively, occurring more often in boys and at older ages. In addition, AORs of sensitization to HDM/JCP were higher in subjects with a history of bronchitis, parental asthma, parental atopic eczema and parental pollinosis. In contrast, AORs for sensitization
\end{abstract}

were lower in those subjected to maternal passive smoking as well as among boys with pets. AORs of sensitization to JCP alone were lower in those with a history of otitis media, those who had been bottle milk fed, and those who were not the firstborn and who lived near a busy road. Conclusion: Sensitization to HDM and JCP was detected in 51 and $39 \%$ of lower-grade schoolchildren, respectively.

(c) 2015 S. Karger AG, Basel

\section{Introduction}

The prevalence of allergies is increasing worldwide, particularly among children [1], with an unprecedented complexity and severity. The common hallmark of allergic disease is the production of serum-specific IgE against allergens, and sensitization to such allergens is a significant risk factor for the subsequent development of allergic diseases [1]. Diagnosing allergic disease or predicting the clinical response to allergy immunotherapy can be facilitated by the assessment of the presence of serum IgE antibodies as markers of allergic sensitization in addition to consultation of a patient's clinical history and physical

\section{KARGER 125}

(c) 2015 S. Karger AG, Base

$1018-2438 / 15 / 1674-0253 \$ 39.50 / 0$

E-Mail karger@karger.com

www.karger.com/iaa
Correspondence to: Dr. Shin Yamazaki

Center for Environmental Health Sciences National Institute for Environmental Studies 16-2 Onogawa, Tsukuba 305-8506 (Japan)

E-Mail yamazaki.shin@ nies.go.jp 
Fig. 1. Participant recruitment flow diaSchoolchildren recruited:

$n=16,274$

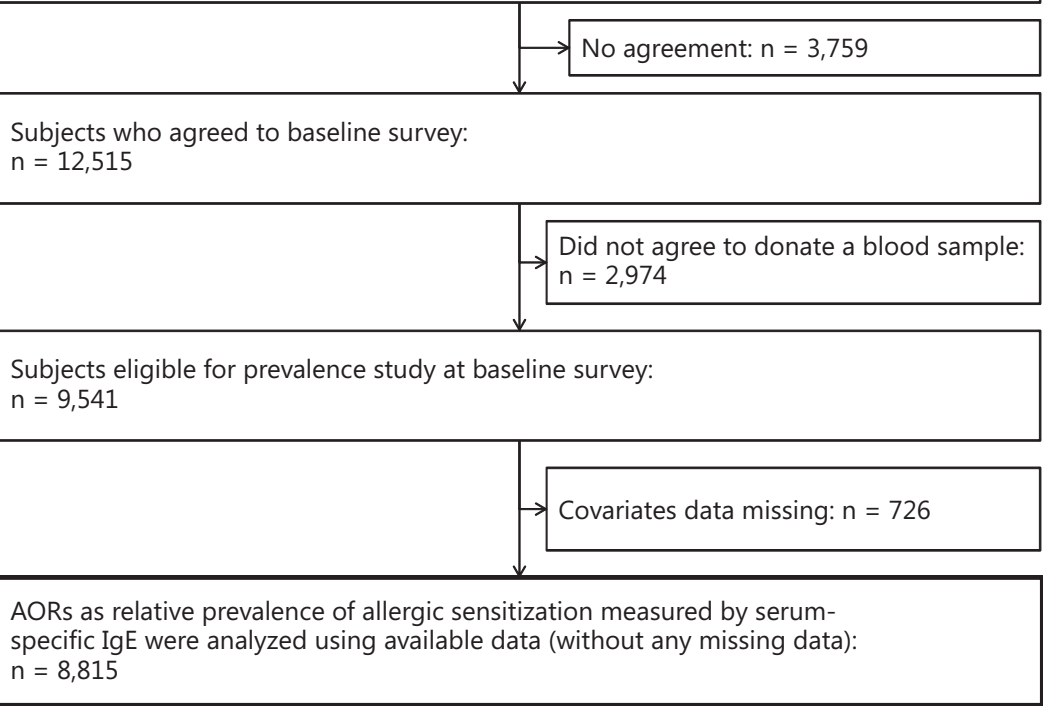
gram.

examination findings [2]. However, while a number of studies have demonstrated an association between allergic sensitization and allergic diseases and described the distribution of serum IgE in children with allergic diseases [3], to our knowledge few large-scale epidemiological studies have been conducted describing the distribution of serum IgE in elementary schoolchildren [4].

Here, we determined the distribution of IgE antibodies specific to two major inhalant allergens in Japan - serum house dust mite (HDM), Dermatophagoides pteronyssinus, and Japanese cedar pollen (JCP) - as markers of sensitization in lower-grade schoolchildren. In addition, we also explored factors associated with allergic sensitization.

\section{Methods}

This cross-sectional study used a database from the Study on Respiratory Disease and Automobile Exhaust (SORA), a Japanese health study project which was funded by the Japanese Ministry of the Environment and attempted to clarify the relationship between traffic-related air pollutants and respiratory diseases and related symptoms [5]. Subjects of the database were all first- to third-year pupils (aged 6-9 years) at 57 elementary schools in 11 cities in 6 geographical areas of Japan in 2005. Of the 57 schools, 49 were preselected due to their proximity to heavy-traffic roads, and the remaining 8 had no heavy-traffic roads in their school districts but were still located in the same administrative district as the initially selected 49 schools.

Other than serum IgE levels, all data on the children's health, parental history of allergy and subject characteristics were obtained through questionnaires completed by the subjects' parents. We incorporated respiratory health items from a standardized questionnaire (ATS-DLD-78) translated into Japanese [6]. The ethical review boards of the Japanese Ministry of the Environment approved the study protocol, and written informed consent for this study, including consent to blood sampling, was obtained from all subjects' parents.

\section{Assessment of Serum IgE Levels}

Blood samples $(4 \mathrm{ml})$ collected from each subject were analyzed using a Phadia ImmunoCAP (Phadia, Uppsala, Sweden), now known as an ImmunoCAP Specific IgE (Phadia, Thermo Scientific). Samples were tested for the presence of serum IgE antibodies to two representative inhalant allergens (HDM and JCP, which are major allergens among Japanese children). All samples were analyzed using the same lot reagent in one central laboratory. The threshold for a positive test result, which was considered indicative of allergic sensitization, was set at a serum-specific IgE level of 0.35 $\mathrm{kU} / \mathrm{l}$ for both allergens. The cut-off was not based on clinical relevance, but was instead chosen based on its function as a reference in many previous studies.

\section{Statistical Methods}

Descriptive analysis and predictive modeling were performed with SAS (version 9.4; SAS Institute, Cary, N.C., USA). We first described the demographic characteristics of the subjects, distributing subjects into 1 of 7 categories each based on serum HDM- 
and JCP-specific IgE levels (class $0:<0.35 \mathrm{kU} / \mathrm{l}$, class 1: 0.35-0.69 $\mathrm{kU} / \mathrm{l}$, class 2: $0.7-3.49 \mathrm{kU} / \mathrm{l}$, class $3: 3.5-17.49 \mathrm{kU} / \mathrm{l}$, class $4: 17.5-$ $49.9 \mathrm{kU} / \mathrm{l}$, class 5: 50.0-99.9 kU/l, class 6: $\geq 100.0 \mathrm{kU} / \mathrm{l}$ ), with distribution stratified by sex and school grade. We also described the prevalence of asthma, pollinosis and other allergic diseases (urticaria, atopic eczema, food allergy and perennial allergic rhinitis) stratified by HDM- and JCP-specific IgE levels.

Next, we determined the factors associated with allergic sensitization using logistic regression and calculated adjusted odds ratios (AORs) as the relative prevalence of allergic sensitization. The explanatory variables were sex, school grade (age), symptom presence (persistent cough, persistent phlegm), history of sinusitis, history of bronchitis, history of pneumonia, history of otitis media, history of tonsillectomy, history of parental allergy (asthma, atopic eczema, pollinosis), feeding during lactation period, birth order and sibling status, source of passive smoking in house, presence of pets (including dogs, hamsters, cats, birds, etc.), flooring material in the child's room, living area and resident group. These were divided into three groups as follows: subjects living in the school district of the 8 elementary schools not located near heavytraffic roads ('reference area'); subjects living in the school district of 49 elementary schools located near heavy-traffic roads and living within $50 \mathrm{~m}$ of a busy road (' $<50 \mathrm{~m}$ zone'), and subjects living in the school district of 49 elementary schools located near heavy-traffic roads and living $\geq 50 \mathrm{~m}$ from a busy road (' $\geq 50 \mathrm{~m}$ zone') [5].

We also calculated AORs by sex and the prevalence of asthma, pollinosis and other allergic diseases, including atopic eczema, for each class of HDM- and JCP-specific IgE levels.

\section{Results}

Of the 16,273 schoolchildren who were potential subjects (fig. 1), 12,515 agreed to participate in this study and returned the baseline questionnaire, with 9,541 further agreeing to the blood sampling. Of those, we analyzed the 8,815 subjects without any missing variables.

Table 1 describes the subject characteristics. Of the 2,166 subjects who had pets (table 1), the numbers of owners of dogs, hamsters, cats and birds were $856(40 \%)$, $495(23 \%), 333(15 \%)$ and $234(11 \%)$, respectively. Figure 2 shows the distribution of subjects in the 7 serum HDM(fig. 2a) and JCP-specific IgE level categories (fig. 2b); distribution is also described in this figure according to sex and school grade. With regard to rates of sensitization, $51 \%$ of the subjects were sensitive to HDM and 39\% to JCP - typically boys and older individuals.

Table 2 shows the prevalence of asthma, pollinosis and other allergic diseases (urticaria, atopic eczema, food allergy and perennial allergic rhinitis) according to serum HDM- and JCP-specific IgE classes, respectively. Doseresponse relationships were observed between the prevalence of allergic diseases and serum HDM-specific IgE
Table 1. General characteristics of the subjects $(n=8,815)$

\begin{tabular}{|c|c|c|}
\hline & $\mathrm{n}$ & $\%$ \\
\hline Male & 4,541 & 51.5 \\
\hline \multicolumn{3}{|l|}{ School grade } \\
\hline 1st (aged 6-7 years) & 3,006 & 34.1 \\
\hline 2nd (aged $7-8$ years) & 2,887 & 32.8 \\
\hline 3rd (aged 8-9 years) & 2,922 & 33.1 \\
\hline \multicolumn{3}{|l|}{ Symptom presence } \\
\hline Persistent cough & 168 & 1.9 \\
\hline Persistent phlegm & 103 & 1.2 \\
\hline Asthma & 423 & 4.8 \\
\hline Allergic disease (pollinosis) & 1,577 & 17.9 \\
\hline Allergic disease (other) & 4,833 & 54.8 \\
\hline History of sinusitis & 1,154 & 13.1 \\
\hline History of bronchitis & 2,256 & 25.6 \\
\hline History of pneumonia & 845 & 9.6 \\
\hline History of pertussis & 49 & 0.6 \\
\hline History of otitis media & 3,428 & 38.9 \\
\hline History of tonsillectomy & 145 & 1.6 \\
\hline History of parental asthma & 1,586 & 18.0 \\
\hline History of parental atopic eczema & 1,187 & 13.5 \\
\hline History of parental pollinosis & 4,298 & 48.8 \\
\hline \multicolumn{3}{|l|}{ Feeding during lactation period } \\
\hline Breast milk & 3,756 & 42.6 \\
\hline Bottle (cow's) milk & 1,129 & 12.8 \\
\hline Mixture & 3,930 & 44.6 \\
\hline \multicolumn{3}{|l|}{ Birth order and sibling status } \\
\hline Firstborn with no siblings & 1,375 & 15.6 \\
\hline Firstborn with siblings & 3,382 & 38.4 \\
\hline Not firstborn & 4,058 & 46.0 \\
\hline \multicolumn{3}{|l|}{ Source of passive smoking in house } \\
\hline Mother & 1,161 & 13.2 \\
\hline Other & 2,268 & 25.7 \\
\hline Unknown & 1,039 & 11.8 \\
\hline None & 4,347 & 49.3 \\
\hline \multicolumn{3}{|l|}{ Presence of pets } \\
\hline Present & 2,166 & 24.6 \\
\hline Formerly but no longer & 952 & 10.8 \\
\hline Never & 5,697 & 64.6 \\
\hline \multicolumn{3}{|l|}{ Floor material in child's room } \\
\hline Tatami & 4,521 & 51.3 \\
\hline Carpet & 1,575 & 17.9 \\
\hline Wood & 2,719 & 30.8 \\
\hline \multicolumn{3}{|l|}{ Resident group } \\
\hline$<50 \mathrm{~m}^{2}$ zone $\mathrm{a}^{\mathrm{a}}$ & 714 & 8.1 \\
\hline$\geq 50 \mathrm{~m}$ zone $\mathrm{e}^{\mathrm{b}}$ & 6,660 & 75.6 \\
\hline Reference area ${ }^{c}$ & 1,441 & 16.3 \\
\hline \multicolumn{3}{|l|}{ Living area } \\
\hline Chiba & 1,123 & 12.7 \\
\hline Setagaya & 1,609 & 18.3 \\
\hline Kawasaki & 1,162 & 13.2 \\
\hline Chukyo (Nagoya) & 1,626 & 18.4 \\
\hline Northern Osaka & 786 & 8.9 \\
\hline Hanshin & 2,509 & 28.5 \\
\hline
\end{tabular}

${ }^{a}$ Subjects living in the school district of 49 elementary schools located near busy roads and living $<50 \mathrm{~m}$ from those roads.

${ }^{\mathrm{b}}$ Subjects living in the school district of 49 elementary schools located near busy roads and living $\geq 50 \mathrm{~m}$ from those roads.

c Subjects living in the school district of the 8 elementary schools not located near busy roads. 
Fig. 2. Distribution of HDM- (a) and JCP(b) specific IgE class among Japanese schoolchildren.

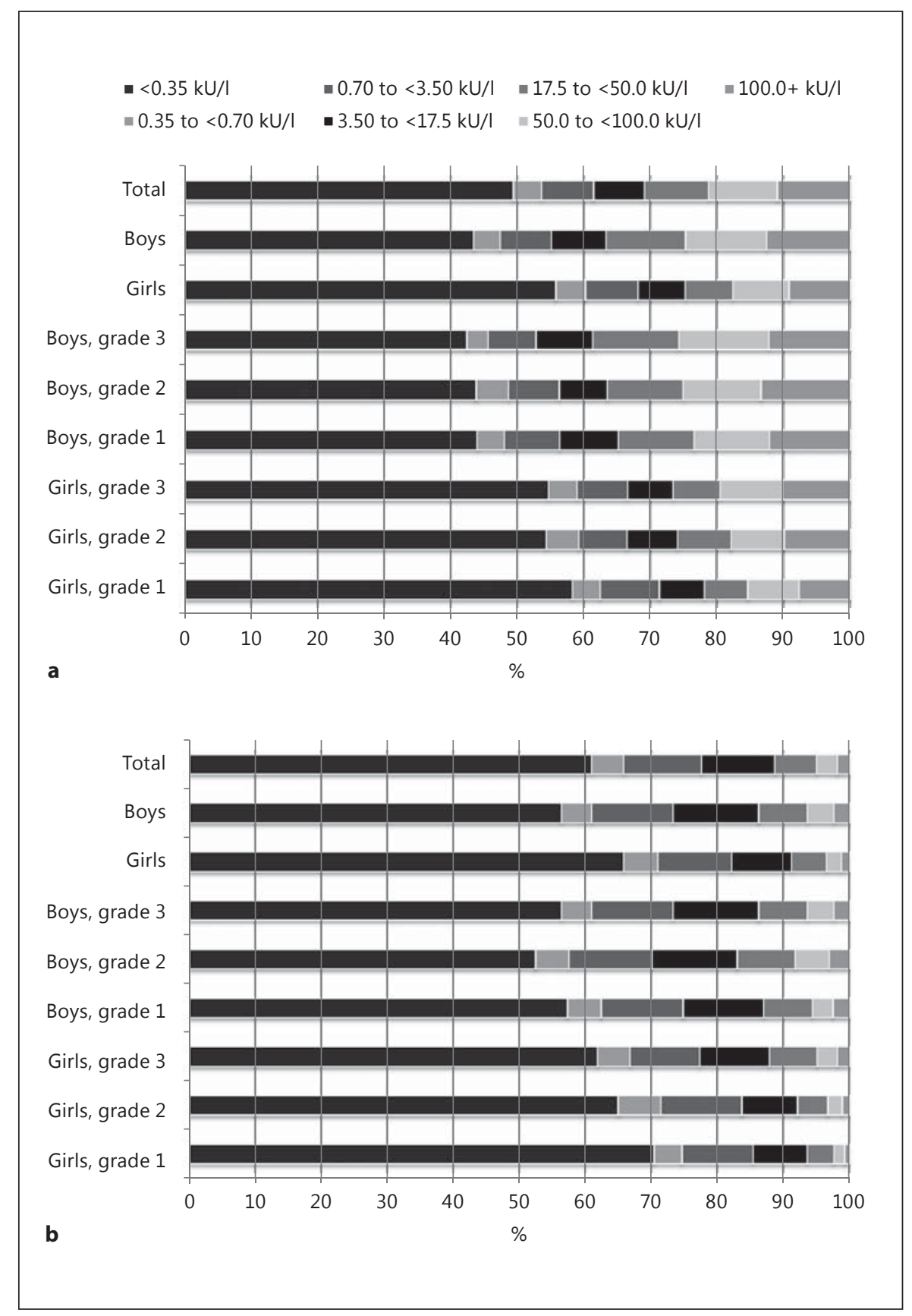

class, as well as between the prevalence of allergic diseases and serum JCP-specific IgE class.

Tables 3 and 4 show the results of multivariate logistic regression models. AORs of sensitization to HDM were higher in boys, older subjects (higher school grade) and those with a history of bronchitis, parental asthma, parental atopic eczema and parental pollinosis (table 3 ). In contrast, AORs of sensitization to HDM were lower in those with a history of tonsillectomy or who lived with a smoker. AORs of sensitization to JCP were higher in boys, older subjects (higher school grade), firstborn or only children, and those with a history of bronchitis, parental asthma, parental atopic disease and parental pollinosis (table 4). In addition, while AORs of sensitization to JCP were lower in those living near heavy-traffic areas, no association was noted between HDM sensitization 
and living area. In contrast, AORs of sensitization to JCP were lower in those with a history of tonsillectomy or otitis media, who had been bottle fed (with cow's milk), who lived with a mother who smoked, who had Japanese tatami flooring (a straw-based Japanese floor covering) in their room (versus wooden flooring) and who had pets.

When we calculated AORs for HDM sensitization among boys, the significant associations with grade of school, history of tonsillectomy and parental pollinosis disappeared, while significant inverse associations with history of otitis media and having pets newly appeared (online suppl. table 1; for all online suppl. material, see www.karger.com/doi/10.1159/000439534). Similarly, when we calculated AORs for HDM sensitization among girls, the significant associations with history of tonsillectomy and having a mother who smoked disappeared (online suppl. table 1). When we calculated AORs for JCP sensitization among boys, the significant associations with being bottle fed (cow's milk) and flooring material in the child's room disappeared (online suppl. table 2). Similarly, when we calculated AORs for JCP sensitization among girls, the significant associations with history of otitis media and tonsillectomy, being bottle fed (cow's milk), having pets and the flooring material of the child's room also disappeared (online suppl. table 2). Of note, the effect of school grade (age) on AORs for both HDM and JCP sensitization was stronger among girls than boys.

Data analysis highlighted the differences in characteristics between the 8,815 included subjects and 3,700 excluded subjects. The proportion of subjects with sinusitis or otitis media was lower among excluded subjects than included subjects, as was the proportion of subjects whose parents had pollinosis. In contrast, proportions of subjects who were bottle fed, had siblings and lived in heavytraffic areas were higher among excluded subjects than included subjects.

\section{Discussion}

Here, we determined the distribution of serum-specific IgE as a marker of sensitization to HDM and JCP among lower-grade schoolchildren. HDM and JCP sensitization was detected in 51 and $39 \%$ of the children examined, respectively. Dose-response relationships were noted between the prevalence of allergic diseases and both the serum HDM-specific IgE class and serum JCPspecific IgE class. Sensitization was associated with male sex, older age (higher grade) and parental history of al-
Table 2. Prevalence of allergic disease according to 7 specific $\operatorname{IgE}$ categories

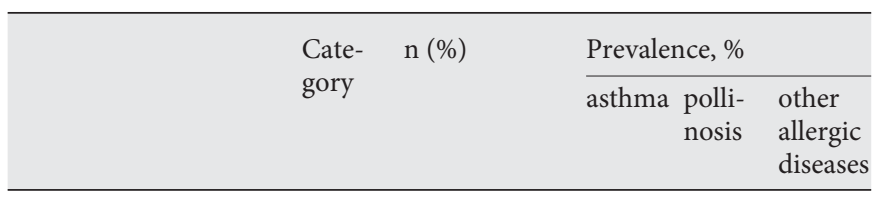

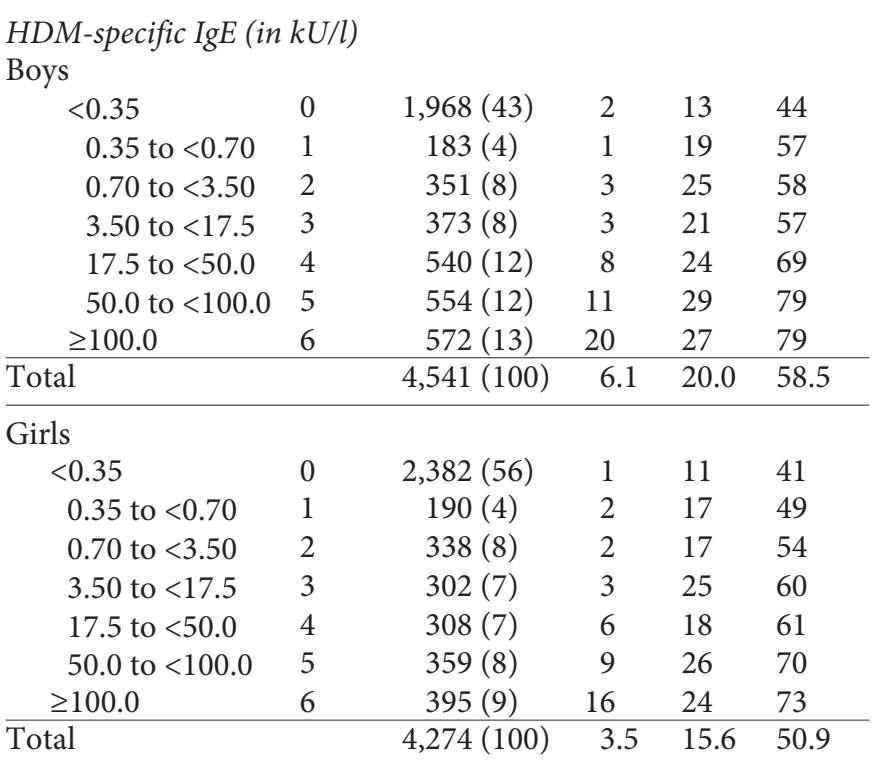

JCP-specific IgE (in $k U / l)$

Boys

\begin{tabular}{llcrrr}
$<0.35$ & 0 & $2,558(56)$ & 4 & 9 & 47 \\
0.35 to $<0.70$ & 1 & $208(5)$ & 5 & 20 & 59 \\
0.70 to $<3.50$ & 2 & $559(12)$ & 9 & 18 & 72 \\
3.50 to $<17.5$ & 3 & $590(13)$ & 10 & 31 & 73 \\
17.5 to $<50.0$ & 4 & $333(7)$ & 10 & 50 & 77 \\
50.0 to $<100.0$ & 5 & $184(4)$ & 8 & 59 & 81 \\
$\geq 100.0$ & 6 & $109(2)$ & 12 & 62 & 83 \\
\hline Total & & $4,541(100)$ & 6 & 20 & 59 \\
\hline Girls & & & & & \\
$<0.35$ & 0 & $2,810(66)$ & 2 & 8 & 43 \\
0.35 to $<0.70$ & 1 & $222(5)$ & 5 & 18 & 59 \\
0.70 to $<3.50$ & 2 & $479(11)$ & 6 & 18 & 60 \\
3.50 to $<17.5$ & 3 & $387(9)$ & 9 & 27 & 65 \\
17.5 to $<50.0$ & 4 & $224(5)$ & 7 & 51 & 78 \\
50.0 to $<100.0$ & 5 & $99(2)$ & 5 & 63 & 77 \\
$\geq 100.0$ & 6 & $53(1)$ & 8 & 74 & 77 \\
\hline Total & & $4,274(100)$ & 4 & 16 & 51 \\
\hline
\end{tabular}

lergic diseases. Sensitization to JCP was higher among those living in the reference area than among those living in areas closer to busy roads; sensitization to JCP was inversely associated with a history of tonsillectomy and having a mother who smoked, and was also lower in subjects who had been bottle fed (cow's milk), had a mother 
Table 3. Relative prevalence (AORs) of sensitization to HDM

\begin{tabular}{|c|c|c|c|c|c|}
\hline & $\mathrm{n}$ & $\begin{array}{l}\operatorname{IgE} \geq 0.35 \mathrm{kU} / \mathrm{l}, \\
\mathrm{n}\end{array}$ & $\begin{array}{l}\text { Prevalence, } \\
\%\end{array}$ & $\mathrm{AOR}^{\mathrm{a}}$ & $95 \% \mathrm{CI}$ \\
\hline Male & 4,541 & 2,573 & 56.7 & 1.62 & $1.49-1.76^{*}$ \\
\hline Female & 4,274 & 1,892 & 44.3 & 1 & Ref. \\
\hline \multicolumn{6}{|l|}{ School grade } \\
\hline 3rd (aged 8-9 years) & 2,922 & 1,511 & 51.7 & 1.13 & $1.02-1.26^{*}$ \\
\hline \multicolumn{6}{|l|}{ Symptom presence } \\
\hline Persistent cough & 168 & 112 & 66.7 & 1.42 & $0.98-2.05$ \\
\hline Persistent phlegm & 103 & 70 & 68.0 & 1.27 & $0.79-2.03$ \\
\hline History of sinusitis & 1,154 & 642 & 55.6 & 1.10 & $0.96-1.25$ \\
\hline History of bronchitis & 2,256 & 1,352 & 59.9 & 1.55 & $1.40-1.72 *$ \\
\hline History of tonsillectomy & 145 & 66 & 45.5 & 0.67 & $0.48-0.95^{*}$ \\
\hline History of parental asthma & 1,586 & 949 & 59.8 & 1.45 & $1.30-1.63^{*}$ \\
\hline History of parental atopic eczema & 1,187 & 715 & 60.2 & 1.42 & $1.25-1.62 *$ \\
\hline History of parental pollinosis & 4,298 & 2,265 & 52.7 & 1.11 & $1.01-1.21^{*}$ \\
\hline \multicolumn{6}{|l|}{ Feeding during lactation period } \\
\hline Breast milk & 3,756 & 1,909 & 50.8 & 1 & Ref. \\
\hline Bottle (cow's) milk & 1,129 & 536 & 47.5 & 0.91 & $0.79-1.05$ \\
\hline Mixture & 3,930 & 2,020 & 51.4 & 1.02 & $0.93-1.12$ \\
\hline \multicolumn{6}{|l|}{ Birth order and sibling status } \\
\hline Firstborn with no siblings & 1,375 & 699 & 50.8 & 1.02 & $0.90-1.16$ \\
\hline Firstborn with siblings & 3,382 & 1,724 & 51.0 & 0.97 & $0.88-1.07$ \\
\hline Present & 2,166 & 1,063 & 49.1 & 0.91 & $0.82-1.01$ \\
\hline Formerly but no longer & 952 & 466 & 48.9 & 0.92 & $0.80-1.07$ \\
\hline Never & 5,697 & 2,936 & 51.5 & 1 & Ref. \\
\hline \multicolumn{6}{|l|}{ Floor material in child's room } \\
\hline Tatami & 4,521 & 2,299 & 50.9 & 1.00 & $0.91-1.11$ \\
\hline Carpet & 1,575 & 773 & 49.1 & 0.94 & $0.82-1.06$ \\
\hline Wood & 2,719 & 1,393 & 51.2 & 1 & Ref. \\
\hline \multicolumn{6}{|l|}{ Resident group } \\
\hline$<50 \mathrm{~m}$ zone $\mathrm{b}^{\mathrm{b}}$ & 714 & 368 & 51.5 & 1.08 & $0.90-1.30$ \\
\hline$\geq 50 \mathrm{~m} \mathrm{zone}^{\mathrm{c}}$ & 6,660 & 3,365 & 50.5 & 1.03 & $0.91-1.16$ \\
\hline Reference area $^{\mathrm{d}}$ & 1,441 & 732 & 50.8 & 1 & Ref. \\
\hline \multicolumn{6}{|l|}{ Living area } \\
\hline Chiba & 1,123 & 594 & 52.9 & 1.11 & $0.95-1.28$ \\
\hline Setagaya & 1,609 & 840 & 52.2 & 1.03 & $0.90-1.17$ \\
\hline Kawasaki & 1,162 & 576 & 49.6 & 0.94 & $0.82-1.09$ \\
\hline Chukyo (Nagoya) & 1,626 & 790 & 48.6 & 0.95 & $0.84-1.08$ \\
\hline Northern Osaka & 786 & 405 & 51.5 & 1.06 & $0.90-1.24$ \\
\hline Hanshin & 2,509 & 1,260 & 50.2 & 1 & Ref. \\
\hline
\end{tabular}

(For footnote see next page.) 
who smoked, had Japanese tatami flooring in their room (versus wooden flooring), and who had pets.

\section{Influence of HDM/JCP-Specific IgE Class on the} Prevalence of Asthma and Other Allergic Diseases

A dose-response relationship between exposure to HDM and the development and severity of asthma has been previously demonstrated $[7,8]$, and despite the cross-sectional nature of the present study, our findings supported those of previous studies. In addition, our study suggested a dose-response association between serum levels of both HDM- and JCP-specific IgE and the prevalence of pollinosis and other allergic diseases.

\section{Influence of Allergies in Parents on Children's Allergic Sensitization}

A number of studies have demonstrated an association between allergies in parents and their offspring [9-11]. Indeed, serum IgE levels in both boys and girls have been found to be associated with their mother's serum IgE level $[10,11]$. In our study, while we did not measure parental serum IgE levels, we evaluated the history of parental symptoms of allergic disease and found that a parental history of symptoms was associated with children's allergic sensitization. We believe the results of our present study are supported by these previous findings [9-11].

\section{Hygiene Hypothesis}

The hygiene hypothesis posits that the rising prevalence of allergic disease is due to a reduction in exposure to infectious agents in modern industrialized society [12, 13]. In our study, not being firstborn, exposure to passive smoking, keeping pets and living near busy roads were factors related to decreased AORs of allergic sensitization. These results may be explained by the hygiene hypothesis.

\section{Influence of Birth Order on Allergic Sensitization}

In our study, firstborn children had a higher rate of sensitization to JCP than children with elder siblings. A recent large cohort study reported an inverse trend for the presence of allergic disease (such as hay fever/eczema) with an increasing number of total siblings, specifically older siblings [12]. These findings lend support to the hygiene hypothesis as an explanation for the increased incidence of allergic diseases [13].

\section{Influence of Breast-Feeding on Allergic Sensitization}

Previous studies have shown that the introduction of milk other than breast milk before 4 months of age is a significant risk factor for all asthma- and atopy-related outcomes in children up to 6 years of age $[14,15]$. However, conflicting results have also been reported, with another study stating that breast-feeding for at least 4 weeks does not protect children from atopy and asthma and may even increase the risk [16]. Of note, however, a review article [17] remarked that the methods and data presented in that particular study do not seem to confirm the conclusion.

The findings of our present study do indeed suggest an association between a reduced prevalence of sensitization to JCP and bottle (cow's milk) feeding - or conversely, that the prevalence of sensitization to JCP is increased with breast-feeding. The relatively high rate of sensitization to JCP observed in breast-fed children may have been due to allergic mothers more often choosing to breast-feed than nonallergic mothers, in the hopes of reducing the risk of allergies in their offspring. However, a significant association between being breast-fed and sensitization to JCP was observed when we calculated odds ratios after adjusting for parental history of allergic diseases and other factors (table 4).

\section{Influence of Exposure to Secondhand Smoke on}

Allergic Sensitization

A causal relationship has been noted between parental (particularly maternal) smoking and an increased incidence of wheezing and asthma in children [18-20]. One study demonstrated an association between passive

(Footnote to table 3)

$* \mathrm{p}<0.05$.

a Relative prevalence of sensitization to HDM. Explanatory variables were: gender, school grade, symptom presence, feeding during lactation period, birth order and sibling status, source of passive smoking in house, presence of pets, flooring material in the child's room, resident group and living area.

b Subjects living in the school district of 49 elementary schools located near busy roads and living $<50 \mathrm{~m}$ from those roads.

c Subjects living in the school district of 49 elementary schools located near busy roads and living $\geq 50 \mathrm{~m}$ from those roads.

${ }^{\mathrm{d}}$ Subjects living in the school district of the 8 elementary schools not located near busy roads.

Patterns of Sensitization to Inhalant Allergens
Int Arch Allergy Immunol 2015;167:253-263 DOI: $10.1159 / 000439534$ 
Table 4. Relative prevalence (AORs) of sensitization to JCP

\begin{tabular}{|c|c|c|c|c|c|}
\hline & $\mathrm{n}$ & $\underset{\mathrm{n}}{\operatorname{IgE} \geq 0.35 \mathrm{kU} / \mathrm{l},}$ & $\begin{array}{l}\text { Prevalence, } \\
\%\end{array}$ & $\mathrm{AOR}^{\mathrm{a}}$ & $95 \% \mathrm{CI}$ \\
\hline Male & 4,541 & 1,983 & 43.7 & 1.50 & $1.37-1.64^{*}$ \\
\hline Female & 4,274 & 1,464 & 34.3 & 1 & Ref. \\
\hline \multicolumn{6}{|l|}{ School grade } \\
\hline 3rd (aged 8-9 years) & 2,922 & 1,258 & 43.1 & 1.43 & $1.28-1.59^{*}$ \\
\hline \multicolumn{6}{|l|}{ Symptom presence } \\
\hline Persistent cough & 168 & 80 & 47.6 & 1.01 & $0.70-1.44$ \\
\hline Persistent phlegm & 103 & 54 & 52.4 & 1.36 & $0.87-2.14$ \\
\hline History of sinusitis & 1,154 & 501 & 43.4 & 1.00 & $0.88-1.14$ \\
\hline History of bronchitis & 2,256 & 1,024 & 45.4 & 1.35 & $1.22-1.50 *$ \\
\hline History of tonsillectomy & 145 & 47 & 32.4 & 0.63 & $0.44-0.90^{*}$ \\
\hline History of parental asthma & 1,586 & 707 & 44.6 & 1.24 & $1.11-1.39^{*}$ \\
\hline History of parental atopic eczema & 1,187 & 588 & 49.5 & 1.52 & $1.34-1.73 *$ \\
\hline History of parental pollinosis & 4,298 & 1,872 & 43.6 & 1.30 & $1.19-1.42 *$ \\
\hline \multicolumn{6}{|l|}{ Feeding during lactation period } \\
\hline Breast milk & 3,756 & 1,497 & 39.9 & 1 & Ref. \\
\hline Bottle (cow's) milk & 1,129 & 396 & 35.1 & 0.84 & $0.72-0.96^{*}$ \\
\hline Mixture & 3,930 & 1,554 & 39.5 & 0.97 & $0.88-1.07$ \\
\hline \multicolumn{6}{|l|}{ Birth order and sibling status } \\
\hline Firstborn with no siblings & 1,375 & 580 & 42.2 & 1.38 & $1.21-1.57^{*}$ \\
\hline Firstborn with siblings & 3,382 & 1,420 & 42.0 & 1.29 & $1.17-1.42 *$ \\
\hline Present & 2,166 & 781 & 36.1 & 0.83 & $0.75-0.93 *$ \\
\hline Formerly but no longer & 952 & 355 & 37.3 & 0.91 & $0.78-1.05$ \\
\hline Never & 5,697 & 2,311 & 40.6 & 1 & Ref. \\
\hline \multicolumn{6}{|l|}{ Floor material in child's room } \\
\hline Tatami & 4,521 & 1,712 & 37.9 & 0.90 & $0.81-0.99 *$ \\
\hline Carpet & 1,575 & 592 & 37.6 & 0.91 & $0.80-1.04$ \\
\hline Wood & 2,719 & 1,143 & 42.0 & 1 & Ref. \\
\hline \multicolumn{6}{|l|}{ Resident group } \\
\hline$<50 \mathrm{~m}$ zone ${ }^{\mathrm{b}}$ & 714 & 271 & 38.0 & 0.77 & $0.64-0.94 *$ \\
\hline$\geq 50 \mathrm{~m} \mathrm{zone}^{\mathrm{c}}$ & 6,660 & 2,526 & 37.9 & 0.78 & $0.69-0.88 *$ \\
\hline Reference area ${ }^{\mathrm{d}}$ & 1,441 & 650 & 45.1 & 1 & Ref. \\
\hline \multicolumn{6}{|l|}{ Living area } \\
\hline Chiba & 1,123 & 490 & 43.6 & 1.69 & $1.45-1.97^{*}$ \\
\hline Setagaya & 1,609 & 709 & 44.1 & 1.69 & $1.48-1.94^{*}$ \\
\hline Kawasaki & 1,162 & 537 & 46.2 & 1.92 & $1.66-2.23 *$ \\
\hline Chukyo (Nagoya) & 1,626 & 650 & 40.0 & 1.62 & $1.42-1.86^{*}$ \\
\hline Northern Osaka & 786 & 307 & 39.1 & 1.53 & $1.29-1.82 *$ \\
\hline Hanshin & 2,509 & 754 & 30.1 & 1 & Ref. \\
\hline
\end{tabular}

(For footnote see next page.) 
smoking and allergic sensitization dependent on the parental allergic status [20]. Among children with two allergic parents, having a mother who smoked regularly significantly increased the odds for allergic sensitization and wheezing in her child compared with children who were never exposed to secondhand smoke [20]. For children with only one allergic parent, the odds were doubled and also statistically significant, whereas in children with no allergic parents, maternal smoking had no effects [20].

Passive smoking has been associated with sensitization to indoor environmental allergens. In particular, maternal smoking during pregnancy is significantly associated with a reduced respiratory function in early infancy and recurrent wheezing during infancy and early childhood [18]. However, conflicting findings have also been reported; one study found no association between passive smoking and serum IgE levels [21], and a recent cross-sectional study showed an association between passive smoke exposure and reduced rates of allergic sensitization [22]. Yet another study demonstrated that parental smoking was associated with a reduced risk of allergic sensitization in people with a family history of atopy [23]. In the present study, we detected an association between passive smoking and a reduced rate of allergic sensitization but were unable to conclude any specific association between passive smoking and allergic conditions due to the crosssectional nature of our study.

\section{Influence of Exposure to Inhalant Allergens (Pets) on Allergic Sensitization}

In the present study, having pets was associated with a decreased sensitization to JCP. In addition, when we calculated AORs stratified by sex, HDM sensitization among boys was inversely associated with having pets. However, previous findings regarding this point are conflicting, with some studies showing that animal exposure during infancy reduces subsequent allergic sensitization $[24,25]$, while others show that animal exposure during infancy increases the risk of a subsequent allergy to those animals [26-28]. Given the cross-sectional nature of our study, we speculate that the association between having pets and decreased sensitization as determined based on JCP- or HDM-associated serum IgE levels may be explained as reverse causation, meaning that allergic subjects (e.g. those with higher JCP/HDM-specific IgE levels) tend not to own pets. One limitation of this study was that we did not investigate pet dander sensitization directly, which would be a more relevant allergen to associate with keeping pets.

\section{Influence of Exposure to Air Pollutants on Allergic Sensitization}

A meta-analysis recently examined the association between air pollution exposure and allergic sensitization to common allergens in children followed prospectively during the first 10 years of life [29], ultimately noting no clear associations. In the present study, however, we did detect an association between the resident group and serum JCP-specific IgE levels. We speculate that subjects with higher serum JCP-specific IgE levels may have tended to live in the reference area, where concentrations of JCP are higher, than in areas nearer to busy roads, which tend to be metropolitan and therefore have lower naturally occurring JCP levels. We also speculate that the level of exposure to HDM in areas near heavytraffic roads does not markedly differ from that in the reference area.

\section{Study Limitations}

Several limitations to the present study warrant mention. First, the cross-sectional design precludes the assessment of temporal and causal relationships. However, while the presence of serum-specific IgE antibodies does not necessarily correspond to clinical allergy, this study demonstrated a clear dose-response associa-

(Footnote to table 4)

$* \mathrm{p}<0.05$

a Relative prevalence of sensitization to JCP. Explanatory variables were: gender, school grade, symptom presence, feeding during lactation period, birth order and sibling status, source of passive smoking in house, presence of pets, flooring material in the child's room, resident group and living area.

b Subjects living in the school district of 49 elementary schools located near busy roads and living $<50 \mathrm{~m}$ from those roads.

${ }^{c}$ Subjects living in the school district of 49 elementary schools located near busy roads and living $\geq 50 \mathrm{~m}$ from those roads.

${ }^{\mathrm{d}}$ Subjects living in the school district of the 8 elementary schools not located near busy roads.

Patterns of Sensitization to Inhalant Allergens
Int Arch Allergy Immunol 2015;167:253-263 DOI: $10.1159 / 000439534$ 
tion between serum-specific IgE levels and the prevalence of allergic diseases. Second, beside serum IgE-level findings, our study may have suffered from some misclassification or recall bias due to the nature of the questionnaire survey. Third, only approximately 59\% of initially eligible subjects agreed to undergo blood sampling. Children without allergic diseases may have been less likely to participate in the present study than those with allergic diseases (selection bias due to nonresponse). Therefore, the distribution of serum IgEs in this study might be higher than in the general population. Fourth, the AORs we calculated might have been overestimated because the prevalence of sensitization was high.

\section{Conclusion}

This study provided information on factors associated with allergic sensitization in lower-grade schoolchildren, with sensitization to HDM and JCP detected in 51 and $39 \%$ of our study population, respectively. Elevated serum-specific IgE levels were associated with older age, male sex, history of bronchitis and parental asthma, parental atopic eczema and parental pollinosis, while decreased levels were associated with a history of tonsillectomy and passive smoking via the mother.

\section{Acknowledgements}

This study was founded by the Japanese Ministry of the Environment. We thank the external review committee: S. Tominaga (chair; Aichi Cancer Center, Japan), S. Akiba (Kagoshima University, Japan), Y. Fukuchi (Juntendo University, Japan), M. Kasahara (Chubu University, Japan), K. Ota (Teikyo University, Japan), A. Morikawa (Gunma University, Japan), M. Shirai (Waseda University, Japan), Y. Yanagisawa (The University of Tokyo, Japan) and I. Yoshimura (Tokyo University of Science, Japan). We also thank the members of the Environmental Health Affairs Office of the Japanese Ministry of the Environment as coordinating officers, and CIMIC Co. Ltd., Tokyo, Japan, for its role as a data center of this study.

\section{Disclosure Statement}

No authors have any conflicts of interest associated with the study.

\section{References}

1 World Allergy Organization (WAO): White book on allergy: update 2013. http://www. worldallergy.org/UserFiles/file/WhiteBook22013-v8.pdf (accessed August 5, 2014).

2 Li Q, Li M, Yue W, Zhou J, Li R, Lin J, Li Y: Predictive factors for clinical response to allergy immunotherapy in children with asthma and rhinitis. Int Arch Allergy Immunol 2014;164:210-217.

3 Hoffmann-Petersen B, Høst A, Larsen KT, Bergstein KR, Thomsen ML, Braendholt V, et al: Prevalence of IgE sensitization in Danish children with suspected asthma. Pediatr Allergy Immunol 2013;24:727-733.

4 Schmitz R, Ellert U, Kalcklösch M, Dahm S, Thamm M: Patterns of sensitization to inhalant and food allergens - findings from the German Health Interview and Examination Survey for Children and Adolescents. Int Arch Allergy Immunol 2013;162:263-270.

5 Yamazaki S, Shima M, Nakadate T, Ohara T, Omori T, Ono M, et al: Association between traffic-related air pollution and development of asthma in school children: cohort study in Japan. J Expo Sci Environ Epidemiol 2014;27: 372-379.

6 Ferris BG: Epidemiology Standardization Project (American Thoracic Society). Am Rev Respir Dis 1978;118:1-120.
7 Melen E, Wickman M, Nordvall SL, HageHamsten M, Lindfors A: Influence of early and current environment exposure factors on sensitization and outcome of asthma in preschool children. Allergy 2001;56:646-652.

8 Sporik R, Sqiollace SP, Ingram JM, Rales G, Honsinger RW, Platts-Mills TA: Mite, cat, cockroach exposure, allergen sensitization, and asthma in children: a case-control study of three schools. Thorax 1999;54:675-680.

-9 Canfield SM, Jacobson JS, Perzanowski MS, Mellins RB, Zemble RM, Chew GL, et al: Total and specific IgE associations between New York City Head Start children and their parents. J Allergy Clin Immunol 2008;121:14221427.

10 Burrows B, Martinezb FD, Cline MG, Lebowitz MD: The relationship between parental and children's serum IgE and asthma. Am J Respir Crit Care Med 1995;152;1497-1500.

11 Liu CA, Wang CL, Chuang H, Ou CY, Hsu TY, Yang KD: Prenatal prediction of infant atopy by maternal but not paternal total IgE levels. J Allergy Clin Immunol 2003;112:899-904.

12 Strachan DP, Ait-Khaled N, Foliaki S, Mallol J, Odhiambo J, Pearce N, et al: Siblings, asthma, rhinoconjunctivitis and eczema: a worldwide perspective from the International Study Of Asthma and Allergies in Childhood. Clin Exp Allergy 2015;45:126-136.
13 Strachan DP: Hay fever, hygiene, and household size. BMJ 1989;299:1259-1260.

$>14$ Oddy WH, Holt PG, Sly PD, Read AW, Landau LI, Stanley FJ, et al: Association between breast feeding and asthma in 6 year old children: finding of a prospective birth cohort study. BMJ 1999;319:815-819.

15 Oddy WH, de Klerk NH, Sly PD, Holt PG: The effects of respiratory infections, atopy, and breastfeeding on childhood asthma. Eur Respir J 2002;19:899-905.

-16 Sears MR, Greene JM, Willan AR, Taylor DR, Flannery EM, Cowan JO, et al: Long-term relation between breastfeeding and development of atopy and asthma in children and young adults: a longitudinal study. Lancet 2002;360:901-907.

17 Halken S: Prevention of allergic disease in childhood: clinical and epidemiological aspects of primary and secondary allergy prevention. Pediatr Allergy Immunol 2004; 15:S9-S32.

18 US Department of Health and Human Services: The health consequences of involuntary exposure to tobacco smoke: a report of the surgeon general. 2006. http://www.ncbi.nlm. nih.gov/books/NBK44324/ (accessed August 5, 2014). 
19 Chilmonczyk BA, Salmun LM, Megathlin KN, Neveux LM, Palomaki GE, Knight GJ, et al: Association between exposure to environmental tobacco smoke and exacerbations of asthma in children. N Engl J Med 1993;328: 1665-1669.

20 Keil T, Lau S, Roll S, Grüber C, Nickel R, Niggemann B, Wahn U, Willich SN, Kulig M: Maternal smoking increases risk of allergic sensitization and wheezing only in children with allergic predisposition: longitudinal analysis from birth to 10 years. Allergy 2009; 64:445-451.

-21 Ciaccio CE, DiDonna AC, Kennedy K, Barnes CS, Portnoy JM, Rosenwasser LJ: Association of tobacco smoke exposure and atopic sensitization. Ann Allergy Asthma Immunol 2013; 111:387-390.
22 Salo PM, Arbes SJ Jr, Jaramillo R, Calatroni A, Weir $\mathrm{CH}$, Sever ML, et al: Prevalence of allergic sensitization in the United States: results from the National Health and Nutrition Examination Survey (NHANES) 2005-2006. J Allergy Clin Immunol 2014;134:350-359.

3 Hancox RJ, Welch D, Poulton R, Taylor DR, McLachlan CR, Greene JM, et al: Cigarette smoking and allergic sensitization: a 32-year population-based cohort study. J Allergy Clin Immunol 2008;121:38-42.e3.

24 Platts-Mills T, Vaughhan J, Squillace S, Woodfolk J, Soirik R: Sensitization, asthma, and a modified Th2 response in children exposed to cat allergen: a population-based cross-sectional study. Lancet 2001;357:752756.

25 Ownby DR, Johnson CC, Peterson EL: Exposure to dogs and cats in the first year of life and risk of allergic sensitization at 6 to 7 years of age. JAMA 2002;288:963-972.
6 Popp W, Rauscher H, Sertl K, Wanke T, Zwick H: Risk factors for sensitization to furred pets. Allergy 1990;45:75-79.

27 Lindfors A, van Hage-Hamsten M, Rietz H, Wickman M, Nordvall SL: Influence of interaction of environmental risk factors and sensitization in young asthmatic children. J Allergy Clin Immunol 1999;104:755-762.

28 Brunekreef B, von Mutius E, Wong G, Odhiambo J, García-Marcos L, Foliaki S, et al: Exposure to cats and dogs, and symptoms of asthma, rhinoconjunctivitis, and eczema. Epidemiology 2012;23:742-750.

29 Gruzieva O, Gehring U, Aalberse R, Agius R, Beelen R, Behrendt $\mathrm{H}$, et al: Meta-analysis of air pollution exposure association with allergic sensitization in European birth cohorts. J Allergy Clin Immunol 2014;133:767-776. 